\title{
A Clinical Study of Laryngeal Cysts
}

\author{
${ }^{1}$ KVS Kumar Chowdary, ${ }^{2} \mathrm{~N}$ Srikanth, ${ }^{3}$ Feroz B Shaik
}

\section{ABSTRACT}

Aim: To study cases of cysts of larynx and review the literature regarding precipitating factors and methods of treatment.

Materials and methods: A retrospective study of eight cases of cysts of larynx in our hospital was carried out from July 2012 to December 2015. In all cases, diagnosis was made by video laryngoscopy and was treated by microlaryngeal surgery under general anesthesia (GA).

Results: Eight patients with laryngeal cysts were identified, of which five were male and three were female. The mean age was ranging from 40 to 60 .

On examination, two were diagnosed with cysts from epiglottis, three from aryepiglottic folds, two from false vocal cords, and one from the ventricle.

Conclusion: As saccular cysts are identified to be associated with neoplastic transformation, it is important to recognize the laryngeal saccular cyst and manage appropriately in its early stages and to differentiate it from other laryngeal cysts. Thorough diagnostic evaluation and surgical intervention necessitates the appropriate management.

Keywords: Ductal cysts, Laryngeal cysts, Microlaryngeal surgery, Saccular cysts.

How to cite this article: Kumar Chowdary KVS, Srikanth N, Shaik FB. A Clinical Study of Laryngeal Cysts. Int J Phonosurg Laryngol 2016;6(2):53-56.

Source of support: Nil

Conflict of interest: None

\section{INTRODUCTION}

Cystic lesions are a common entity among benign lesions of larynx. True cysts of the larynx are a group of benign lesions that are usually recognized on examination and are simply managed. In larynx, cysts may be localized in different regions, i.e., glottis, epiglottis, aryepiglottic folds, true vocal cords, false vocal cords, and subglottic area. Location of the cyst near the orifice of the ventricle or subglottic region results in stridor. Cysts located away

\footnotetext{
${ }^{1}$ Professor, ${ }^{2}$ Assistant Professor, ${ }^{3}$ Postgraduate Student

${ }^{1-3}$ Department of ENT, NRI Medical College, Guntur, Andhra Pradesh, India

Corresponding Author: KVS Kumar Chowdary, Professor Department of ENT, NRI Medical College, Guntur, Andhra Pradesh, India, Phone: +917893451789, e-mail: chowdaryent@ gmail.com
}

from the inlet of the glottis, for example in the vallecula, and present initially with feeding problems, whereas stridor develops after some time only. ${ }^{1,2}$

The laryngeal cysts represent a mixed group of benign lesions that can cause diagnostic and therapeutic difficulties. In general, laryngeal cysts were found to be collection of homogenous lesions from different histogenic origins with diverse symptoms related to their site and size. Cysts appear clinically as spherical bugles covered by smooth epithelium. Symptoms produced include hoarseness, foreign body sensation, and dyspnea, but are rarely life-threatening. Normally, laryngeal cysts are easily diagnosed and removed by microlaryngoscopy.

\section{AIM}

To present a case series of different types of cysts of larynx and review the literature regarding precipitating factors and methods of treatment.

\section{MATERIALS AND METHODS}

A retrospective study of eight cases of cysts of larynx in our hospital, from July 2012 to December 2015, in all cases diagnosis was made by video laryngoscopy and treated by microlaryngeal surgery under general anesthesia (GA).

Age, gender, physical examination, cyst location, treatment used, and outcomes were analyzed and data were correlated.

\section{RESULTS}

Eight patients with laryngeal cysts were identified, of which five were male and three were female. The mean age was ranging from 40 to 60 .

Two patients required medical management before a definitive diagnosis of laryngeal cysts was made as they had edema, hemorrhage, mucosal thickening, and inflammation.

On examination two patients were diagnosed with cysts from epiglottic, three from aryepiglottic folds, two from false vocal cords, and one from the ventricle (Table 1).

Table 1: Total number of cases done

\begin{tabular}{ll}
\hline Total number of cases & 8 \\
\hline No. of ductal cysts & 2 \\
No. of saccular cyst & 6 \\
\hline
\end{tabular}




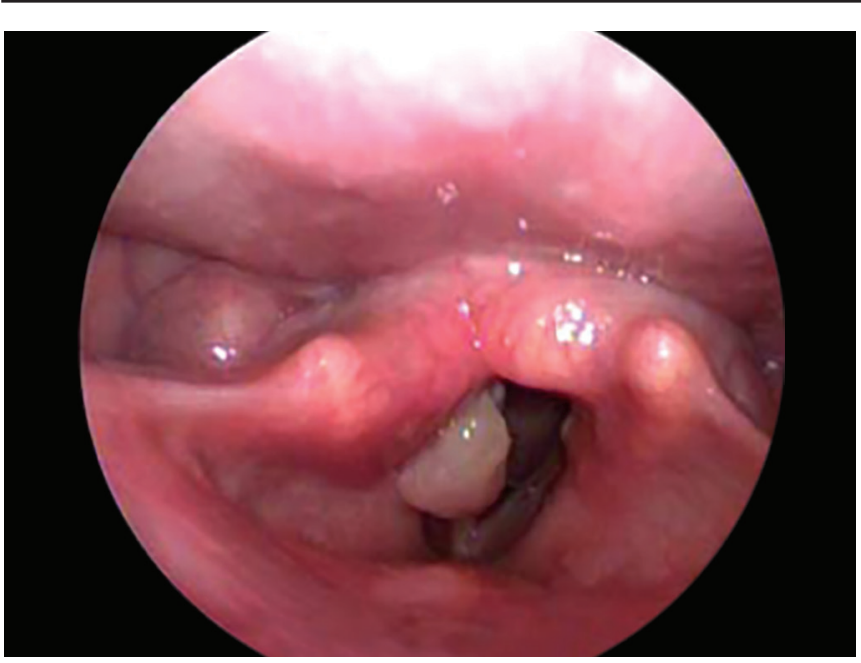

Fig. 1: Aryepiglottic fold

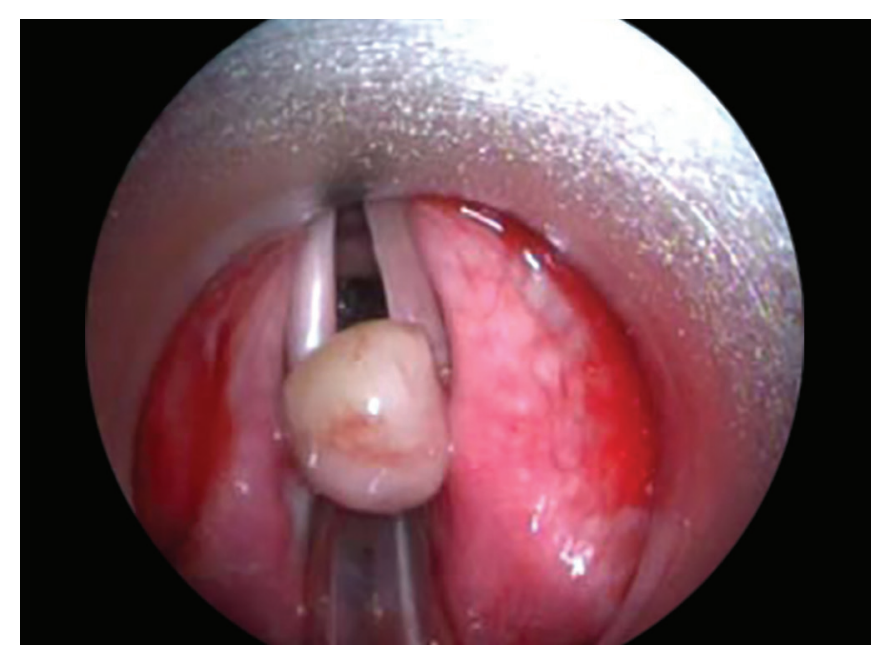

Fig. 3: False vocal cords

The cystic mass rests on anterior commissure and moves during phonation. Though the vocal cord mobility appears normal because of the presence of mass, vocal cords will not adduct completely creating phonatory gap which results in breathy dysphonia.

There was no cervical lymphadenopathy, and systemic examination was normal. Routine hematological and urine investigations were within normal limits. Removal of cysts was done by microlaryngeal surgery or endoscopic excision under GA. The specimen was sent for histopathological examination in all cases (Figs 1 to 4 ).

\section{DISCUSSION}

Saccule is a membranous sac in the larynx, located between the false vocal cords and the inner surface of the thyroid cartilage and containing mucous secreting glands whose secretions lubricates the vocal cords. Obstruction of orifice of the laryngeal saccule or obstruction of the mucous gland ducts of the laryngeal saccule, with subsequent accumulation of secretions results in cyst

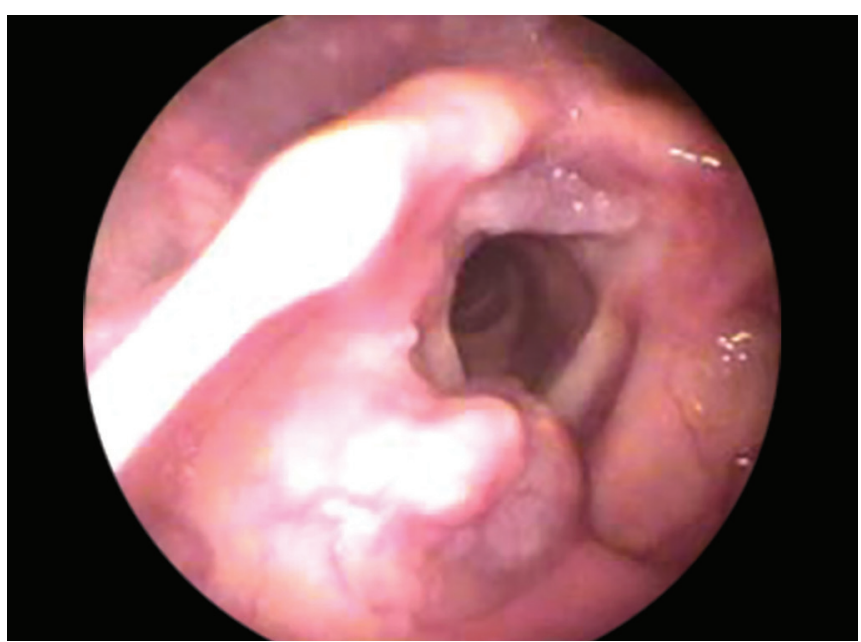

Fig. 2: Epiglottis

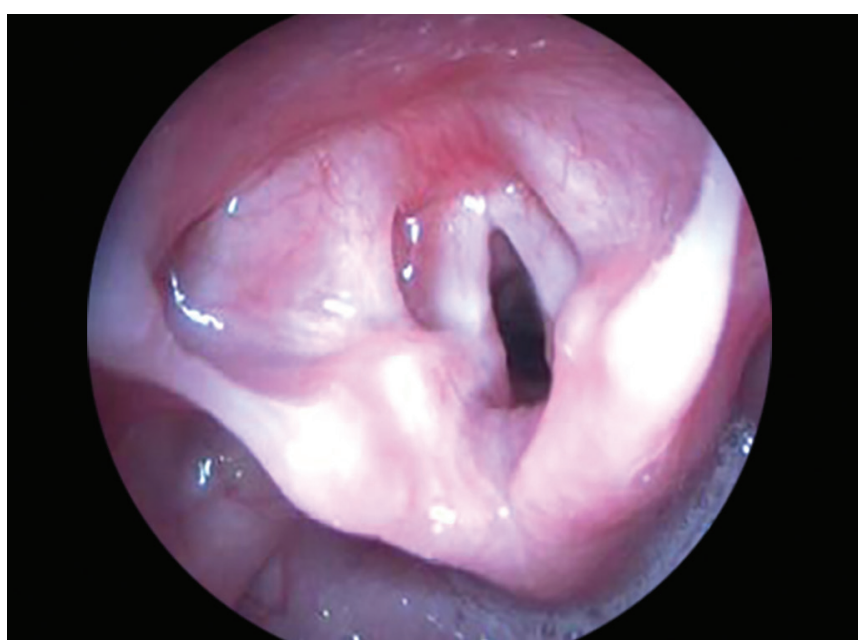

Fig. 4: Ventricle

formation. They may be present congenitally or may develop eventually due to degenerative cause. The first classification of cystic laryngeal lesions was described by Desanto et al. ${ }^{3}$ Laryngeal cysts have been divided into two categories (Table 2).

With no gender predilection, they occur over a wide range of age, but tend to be most common in individuals older than the sixth decade. The majority of cysts occur in the supraglottic larynx, less frequently glottic and subglottic cysts can occur.

Saccular cysts can be further subdivided into anterior and lateral, depending on the location, level of obstruction, and length of the saccule ${ }^{4}$ (Table 3 ).

Other cysts types include tonsillar, epithelial, and oncocytic (Table 4).

In general, laryngeal cysts may be solitary or multiple. Symptoms include:

- Asymptomatic and identified incidentally.

- Hoarseness, coughing, dyspnea, sensation of foreign body in throat, neck mass, and pain.

- Infants may present with feeding problems. 


\begin{tabular}{|c|c|c|}
\hline Sl. no. & Ductal cyst & Saccular cyst \\
\hline 1 & $\begin{array}{l}\text { Due to obstruction of mucous } \\
\text { gland ducts }\end{array}$ & $\begin{array}{l}\text { Due to obstruction } \\
\text { of the orifice of the } \\
\text { laryngeal saccule }\end{array}$ \\
\hline 2 & $\begin{array}{l}\text { Represents } 75 \% \text { of all } \\
\text { laryngeal cysts }\end{array}$ & $\begin{array}{l}\text { Represents } 25 \% \text { of all } \\
\text { laryngeal cysts }\end{array}$ \\
\hline 3 & $\begin{array}{l}\text { Majority occurs in the area of } \\
\text { the true vocal cords, but not in } \\
\text { the region of the free margin } \\
\text { which lacks glands }\end{array}$ & $\begin{array}{l}\text { Occur in the } \\
\text { supraglottic larynx }\end{array}$ \\
\hline 4 & $\begin{array}{l}\text { Next most common site is the } \\
\text { epiglottis }\end{array}$ & $\begin{array}{l}\text { Majority occur in the } \\
\text { region of the ventricles }\end{array}$ \\
\hline 5 & $\begin{array}{l}\text { Less frequent sites include } \\
\text { false focal cords, ventricles, } \\
\text { aryepiglottic folds, arytenoids, } \\
\text { pyriform sinus, anterior } \\
\text { commissure, and subglottis. } \\
\text { They remain asymptomatic if } \\
\text { small, or cause hoarseness, } \\
\text { cough, throat pain, and } \\
\text { dyspnea if large }\end{array}$ & $\begin{array}{l}\text { Less often occur } \\
\text { in the region of the } \\
\text { aryepiglottic folds, } \\
\text { lateral larynx }\end{array}$ \\
\hline
\end{tabular}

Table 3: Types of saccular cysts

\begin{tabular}{|c|c|}
\hline \multicolumn{2}{|c|}{ Saccular cysts } \\
\hline Anterior: & Lateral: \\
\hline $\begin{array}{l}\text { - Develop near the orifice of } \\
\text { the ventricle overhanging } \\
\text { the anterior glottis }\end{array}$ & $\begin{array}{l}\text { - Bulge into the aryepiglottic } \\
\text { folds, false vocal cords, or } \\
\text { epiglottis }\end{array}$ \\
\hline $\begin{array}{l}\text { - Represents the majority } \\
\text { of cases }\end{array}$ & $\begin{array}{l}\text { - Rarely present as a neck mass, } \\
\text { with the cyst extending through } \\
\text { the thyroid membrane }\end{array}$ \\
\hline
\end{tabular}

Table 4: Other laryngeal cysts types

\begin{tabular}{l} 
Other cysts types \\
\hline (i) Tonsillar type: Occur primarily in the epiglottis, vallecula, or \\
pyriform sinus. \\
(ii) Epithelial type: Occur primarily in the pyriform sinus or \\
vallecula. \\
(iii) Oncocytic type: Occur primarily in the false vocal cords and \\
ventricles.
\end{tabular}

\section{Pathology:}

Gross:

- Ductal cysts:

- Usually measure less than $1 \mathrm{~cm}$ in diameter

- Tend to be superficial

- Saccular cysts:

- Submucosal, range in size from 1 to over $7 \mathrm{~cm}$ in greatest dimension

Histology:

A Both ductal and saccular cysts are lined by respiratory or squamous epithelium:

- Differentiation of ductal from saccular cysts is not possible histologically, and so differentiation rests on clinical parameters. Cyst may be lined by an oncocytic epithelium.

B Other histologic cyst types include:
- Tonsillar:

- Resembles palatine tonsillar crypt

- Lined by stratified squamous epithelium

- Keratin-filled lumen

- Lymphoid follicles with germinal centers seen in cyst wall

- Epithelial:

- Lined by respiratory and/or squamous epithelium or a flattened epithelium

- Epithelial lining may be papillary in architecture

- May contain keratin or mucin

- May have a lymphoid component in cyst wall

- Oncocytic:

- Lined by oncocytic epithelium.

- May have prominent papillary architecture and is referred to as oncocytic papillary or cystadenoma - Apart from the above, oncocytic metaplasia and hyperplasia can be seen in association with other laryngeal lesions, and these changes most likely represent a phenomenon of aging. ${ }^{5}$

\section{SURGICAL PROCEDURE}

Hoarseness of voice, airway compromise, and concerns of malignancy are the indications for surgery. ${ }^{6}$ Treatment modalities include endoscopic excision, microlaryngeal surgery, laser excision, needle aspiration, and marsupialization. ${ }^{7}$ Smaller anterior saccular cysts can be managed by endoscopic excision. Complete excision, endoscopically or through an external surgical approach, may shorten the clinical approach. Recurrence is strictly related to maintenance of remains in the cyst wall, therefore total excision is recommended in order to have lower recurrence rates. ${ }^{8}$

\section{CONCLUSION}

As saccular cysts are identified to be associated with neoplastic transformation, it is important to recognize the laryngeal saccular cyst and manage appropriately in its early course of time and differentiate it from other laryngeal cysts. Thorough diagnostic evaluation and surgical intervention necessitates the appropriate management of all cysts of larynx, as not much of it is reported in literature till now. We will be happy if our experience helps in enlightening the fraternity.

\section{REFERENCES}

1. Bais AS, Uppal K, Logani KB. Congenital cysts of the larynx. J Laryngol Otol 1989 Oct;103(10):966-967.

2. Marien S, Jespers A, Vidts G, Schmelzer B. Congenital laryngeal cyst: a case report. Acta Otorhinolaryngol Belg 2003;57(2):119-121.

3. DeSanto LW, Devikine KD, Weiland LH. Cysts of the larynx - classification. Laryngoscope 1970 Jan;80(1):145-176. 
4. Ramesar K, Albizzati C. Laryngeal cysts; clinical relevance of a modified working classification. J Larnygol Otol 1988 Oct;102(10):923-925.

5. Tucker, H.M. Degenerative disorders of the larynx. In: Tucker, H.M., editor. The larynx. New York: Thieme Medical; 1987. p. 209-220.

6. Rosen, C.A.; Simpson, C.B. Principles of microlaryngoscopy. In: Operative techniques in laryngology. Pittsburgh, PA: Springer; 2008. p. 1.
7. Kumar S, Garg S, Sahni JK. Radiofrequency ablation of laryngeal saccular cyst in infants: a series of six cases. Int J Pediatr Otorhinolarnygol 2012 May;76(5): 667-669.

8. Danish HMN, Meleca RJ, Dworkin JP, Abbarah TR. Laryngeal obstructing saccular cysts: a review of this disease and treatment approach emphasizing complete endoscopic carbon dioxide laser excision. Arch Otolaryngol Head Neck Surg 1998 May;124(5):593-596. 